\title{
Night admission is an independent risk factor for mortality in trauma patients - a systemic error approach
}

\section{Admissão noturna é fator de risco independente para mortalidade em pacientes vítimas de trauma - uma abordagem ao erro sistêmico}

Leonardo de Souza Barbosa'; Geibel Santos dos Reis Júniori'; Ricardo Zantieff Topolski Chaves'i; Davi Jorge Fontoura Solla'; Leonardo Fernandes Canedo²; André Gusmão Cunha²

\section{A}

\begin{abstract}
Objective: to assess the impact of the shift inlet trauma patients, who underwent surgery, in-hospital mortality. Methods: a retrospective observational cohort study from November 2011 to March 2012, with data collected through electronic medical records. The following variables were statistically analyzed: age, gender, city of origin, marital status, admission to the risk classification (based on the Manchester Protocol), degree of contamination, time / admission round, admission day and hospital outcome. Results: during the study period, 563 patients injured victims underwent surgery, with a mean age of 35.5 years ( \pm 20.7$)$, 422 (75\%) were male, with $276(49.9 \%)$ received in the night shift and 205 (36.4\%) on weekends. Patients admitted at night and on weekends had higher mortality $[19(6.9 \%)$ vs. $6(2.2 \%), p=0.014$, and $11(5.4 \%)$ vs. $14(3.9 \%), p=0.014$, respectively]. In the multivariate analysis, independent predictors of mortality were the night admission (OR 3.15), the red risk classification (OR 4.87), and age (OR 1.17). Conclusion: the admission of night shift and weekend patients was associated with more severe and presented higher mortality rate. Admission to the night shift was an independent factor of surgical mortality in trauma patients, along with the red risk classification and age.
\end{abstract}

Key words: Wounds and Injuries. Mortality. Patient Admission. Time Factors. Emergencies.

\section{INTRODUCTION}

\footnotetext{
Twanter
} here is evidence that patients admitted in night shifts, weekends or holidays have higher rates of complications, hospitalization time and mortality ${ }^{1-3}$. Fatigue and lack of supervision to attending physicians may contribute to increased complications and hospital mortality. Such situations, also added to the circadian rhythm and dynamics of abnormal operating changes can be crucial factors for the worst performance in these periods. The cumulative presence of a number of unfavorable conditions is remarkable and very common in these periods, situations that favor and increase vulnerability to error ${ }^{1-10}$.

Specific studies in patients with acute myocardial infarction, ischemic stroke and the Intensive Care Units showed higher rate of clinical complications and hospital mortality in the "off-hours" periods (nighttime or weekends) $)^{4-12}$.

The volume of evidence demonstrating higher incidence of unfavorable outcomes in these adverse conditions weakens the idea of occasional errors as the cause of these events ${ }^{4-10}$. This highlights the need to analyze these situations trough of a model to interpret the error with a systemic view.

Due to the lack of Brazilian studies, this study aimed to verify the impact of the shift of admission of patients who have suffered trauma, underwent surgery, in hospital mortality. According to these results, interpretation models and error correction are discussed.

\section{METHODS}

This is a cohort study with retrospective collection of data, which were selected through electronic medical records, patients admitted from November 2011 to March 2012 in the emergency of Hospital do Subúrbio (HS) - a public hospital attending urgency and emergency and public-private administrative nature, in Subúrbio Ferroviário, district of the city of Salvador, Bahia. The study included trauma patients admitted to the emergency HS who underwent surgery and were classified according to International Classification of Diseases - 10th edition (ICD10) in the postoperative as external causes ${ }^{13}$.

1. Faculdade de Medicina da Bahia da Universidade Federal da Bahia - BA - Brasil; 2. Departamento de Anestesiologia e Cirurgia da Faculdade de Medicina da Bahia da Universidade Federal da Bahia - BA - Brasil. 
This study was submitted to the Ethics Committee of the Faculdade de Medicina of Universidade Federal da Bahia under number 234.541, in addition to having the consent of Hospital do Subúrbio. The signing of an Informed Consent Form was dismissed because of the observational and retrospective nature of the study.

The day shift was defined as from 08:00 to 17:59, the night shift from 18:00 to 07:59 and the weekend as any time from 18:00 on Friday until 07:59 on Monday. The exchange on duty hours were included in the "off hours" period because they have similar organizational adversity.

For statistical analysis, age was treated as a continuous variable. This approach was chosen, rather than dichotomizing in elderly and non-elderly, due to the low average age of the study population. The city of origin was ranked from the state capital, Salvador, or Country towns. The risk classification at admission was defined according to Manchester protocol ${ }^{11}$ and categorized in blue, green, yellow and red, in ascending order of risk. The surgeries were classified as to the degree of contamination $^{12}$ as clean potentially contaminated, contaminated and infected. The admission shift was defined as daytime for patients with incoming record between 08:00 and 18:00 and night at other times and the day of registration, split at the weekend (Saturday and Sunday) or non-weekend. Categorical variables were expressed as their proportions, which were compared using the chi-square test with Yates or Fisher's exact test continuity correction. The means and standard deviations were calculated for continuous variables with normal distribution, which in turn were compared using the Student T test for independent samples or ANOVA, and medians and quartiles for the non-normal, which a comparison was made by the tests non-parametric MannWhitney or Kruskal-Wallis. Multivariate analysis to identify predictors of hospital mortality factors was performed by multiple logistic regression by the method "backward stepwise" with results expressed by Odds Ratios and their confidence intervals $(\mathrm{Cl})$ of $95 \%$. Potential confounding variables identified by univariate analysis with $p$ up to 0.10 were included in the multivariate models, as well as gender variable. All tests were two-tailed and were considered statistically significant results with pd" 0.05 .

\section{RESULTS}

Five hundred sixty-three patients were analyzed (Table 1), with average age of $35.5( \pm 20.7)$ years, of which $422(75 \%)$ were male and $474(84 \%)$ singles. There were 337 (59.8\%) "off-hours" admissions, with 276 night admissions and 205 weekend admissions. For the classification of risk of admission, 226 (47.5\%) were classified as green, 118 (24.8\%) as yellow and 107 (22.5\%) as red. The hospital mortality was $4.4 \%$ (25 patients).

It was observed that at the night shift patients were younger, with an average age of $32.5( \pm 20.7)$ vs. $38.1( \pm 20.1), p=0.001$ and with a tendency to higher proportion of men, $217(78.6 \%)$ vs. $197(71.1 \%), p=0.053$. Most nightly admissions were on weekends, 144 (52.2\%) vs. $59(21.3 \%), p<0.001$. During the night shift, there was a higher number of admissions of patients with single marital status, 250 (94.7\%) vs. 217 (83.8\%), $p<0.001$. According to the rating of risk, the most severe patients were admitted. Besides a larger number of contaminated surgery, 82 (29.7\%) vs. 36 (13\%), p<0.001. Mortality was

Table 1 - Clinical and demographic characteristics of patients admitted to the emergency, daytime vs. nightly and weekdays vs. weekend $(n=563)$.

\begin{tabular}{|c|c|c|c|c|c|c|c|c|c|c|}
\hline \multirow[b]{2}{*}{ Age (average \pm SD) } & \multicolumn{2}{|c|}{$\begin{array}{l}\text { Daytime } \\
(n=277)\end{array}$} & \multicolumn{2}{|c|}{$\begin{array}{c}\text { Nightly } \\
(n=276)\end{array}$} & \multirow{2}{*}{$\begin{array}{c}\text { p Value } \\
0,001\end{array}$} & \multicolumn{2}{|c|}{$\begin{array}{l}\text { Week days } \\
(n=358)\end{array}$} & \multicolumn{2}{|c|}{$\begin{array}{l}\text { Weekends } \\
(n=205)\end{array}$} & \multirow{2}{*}{$\begin{array}{c}\text { p Value } \\
0,011\end{array}$} \\
\hline & 38,1 & $( \pm 20,1)$ & 32,5 & $( \pm 20,7)$ & & 37,13 & $( \pm 21,9)$ & 32,79 & $( \pm 18,0)$ & \\
\hline Male & 197 & $(71,1 \%)$ & 217 & $(78,6 \%)$ & 0,053 & 261 & $(72,9 \%)$ & 161 & $(78,5 \%)$ & 0,167 \\
\hline Admission at the weekend & 59 & $(21,3 \%)$ & 144 & $(52,2 \%)$ & $<0,001$ & - & & - & & - \\
\hline Night Admission & - & & - & & - & 132 & $(37,7 \%)$ & 144 & $(70,9 \%)$ & $<0,001$ \\
\hline From Salvador & 219 & $(79,1 \%)$ & 205 & $(74,3 \%)$ & 0,219 & 279 & $(77,9 \%)$ & 155 & $(75,6 \%)$ & 0,598 \\
\hline Single & 217 & $(83,8 \%)$ & 250 & $(94,7 \%)$ & $<0,001$ & 295 & $(87,0 \%)$ & 179 & $(92,7 \%)$ & 0,058 \\
\hline Risk classification & & & & & $<0,001$ & & & & & 0,041 \\
\hline Green & 128 & $(58,7 \%)$ & 94 & $(37,8 \%)$ & & 155 & $(52,4 \%)$ & 71 & $(39,2 \%)$ & \\
\hline Yellow & 42 & $(19,3 \%)$ & 73 & $(29,3 \%)$ & & 67 & $(22,6 \%)$ & 51 & $(28,2 \%)$ & \\
\hline Red & 38 & $(17,4 \%)$ & 67 & $(26,9 \%)$ & & 61 & $(20,6 \%)$ & 46 & $(25,4 \%)$ & \\
\hline Contaminated Surgery & 36 & $(13,0 \%)$ & 82 & $(29,7 \%)$ & $<0,001$ & 68 & $(19,0 \%)$ & 55 & $(26,8 \%)$ & 0,040 \\
\hline Mortality & 6 & $(2,2 \%)$ & 19 & $(6,9 \%)$ & 0,014 & 14 & $(3,9 \%)$ & 11 & $(5,4 \%)$ & 0,014 \\
\hline
\end{tabular}

Source: electronic medical records, patients admitted from November 2011 to March 2012 in the emergency of Hospital do Subúrbio (HS).

Data are presented as $n(\%)$ valid unless specified.

SD: standard deviation. 
higher in this same group, 19 (6.9\%) vs. $6(2.2 \%), p=0.014$ (Table 1).

It was observed that the weekend patients were younger, with an average age of $32.8( \pm 18.0)$ vs. 37.1 ( \pm 21.9) $p=0.011$. There was no difference according to gender. There was a higher proportion of more severe patients admitted on weekends, as well as greater number of contaminated surgery, 55 (26.8\%) vs. 68 (19\%), $\mathrm{p}=0.040$. Mortality was higher in patients admitted in this period, 11 (5.4\%) vs. 14 (3.9\%), $\mathrm{p}=0.014$ (Table 1).

Patients who had in-hospital death and who have not died were compared (Table 2). It observed that the patients who died had greater age $47.2( \pm 24.2)$ vs. 35.0 $( \pm 20.4), p=0.004$, with no differences according to gender and admission during the weekend. However, it was observed that the patient who died had higher night admission fee, 19 (76\%) vs. 257 (48.7\%), p=0.014; and that these were of highest risk, $p<0.001$.

To identify independent predictors of mortality was conducted multivariate logistic regression analysis.It was retained in the final model the age (for each five years, odds ratio $1.17,95 \%$ confidence interval 1.12 to 1.23 ), red risk classification ( $\mathrm{OR}=4,87, \mathrm{Cl} 95 \%=2,07$ a 11,46$)$ and the night admission (OR=3.15, CI95\% 1.19 to 8.35) (Figure 1).

\section{DISCUSSION}

The study showed that the admission of victims of trauma patients who underwent surgery, occurs with considerable frequency in "off-hours" periods at the HS emergency service, which is also perceived in other trauma services. There were 563 patients in total in a period of four months in a row, with approximately $60 \%$ of admissions in "off-hours" periods.

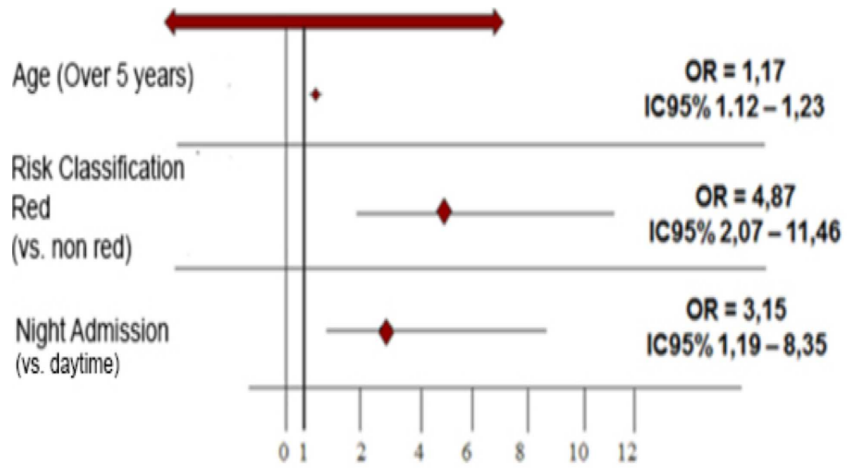

Figura 1 - Independent predictors of hospital mortality.

The "off-hours" periods have a more complex operation and peculiar logistics. Failure to operate in its entirety, with some services not readily available, or even not available, leads to a delay in the execution and difficult logistics service. Some authors have given ${ }^{3-5}$ that the multidisciplinary ratio (medical staff, nursing, pharmacy, laboratory, diagnostic imaging, management etc.) and referral to medical specialists is hampered due to fewer professionals, providing a smaller number diagnostic investigations and therapeutic procedures based on evidence ${ }^{3-6,10,14-16}$. Another factor that may have important association is related to the fatigue of professionals at night, and these are often the same professionals who worked during the day and stay at night, or who may already have come from other working hours; furthermore, the inversion of sleep-wake cycle can change and attention influence the procedures adopted ${ }^{3,17-20}$.

This study, performed in a major hospital in the emergency area, is consistent with data in the literature regarding the morbidity and mortality of patients admitted in different shifts and in the middle or end of the week, showing a higher mortality in patients admitted in the "off-

Table 2 - Clinical and demographic characteristics of patients admitted to the emergency, no deaths vs. death ( $\mathrm{n}=563$ ).

\begin{tabular}{|c|c|c|c|c|c|}
\hline & \multicolumn{2}{|c|}{ No death $(n=538)$} & \multicolumn{2}{|c|}{ Death $(n=25)$} & $\mathrm{p}$ Value \\
\hline Age (average \pm SD) & \multicolumn{2}{|c|}{$35,0( \pm 20,4)$} & \multicolumn{2}{|c|}{$47,2( \pm 24,2)$} & 0,004 \\
\hline Male & 404 & $(75,1 \%)$ & 18 & $(72,0 \%)$ & 0,910 \\
\hline Night Admission & 257 & $(48,7 \%)$ & 19 & $(76,0 \%)$ & 0,014 \\
\hline Admissionat the weekend & 194 & $(36,1 \%)$ & 11 & $(44,0 \%)$ & 0,553 \\
\hline From Salvador & 412 & $(76,6 \%)$ & 22 & $(88,0 \%)$ & 0,278 \\
\hline Single & 453 & $(88,8 \%)$ & 21 & $(95,5 \%)$ & 0,058 \\
\hline Risk classification & & & & & $<0,001$ \\
\hline Blue & 25 & $(5,5 \%)$ & 1 & $(4,0 \%)$ & \\
\hline Green & 222 & $(49,1 \%)$ & 4 & $(16,0 \%)$ & \\
\hline Yellow & 112 & $(24,8 \%)$ & 6 & $(24,0 \%)$ & \\
\hline Red & 93 & $(20,6 \%)$ & 14 & $(56,0 \%)$ & \\
\hline Contaminated Surgery & 116 & $(21,6 \%)$ & 7 & $(28,0 \%)$ & 0,607 \\
\hline
\end{tabular}

Source: electronic medical records, patients admitted from November 2011 to March 2012 in the emergency of Hospital do Subúrbio (HS).

Data are presented as $n$ (\%) valid unless specified.

SD: standard deviation. 
hours" period ${ }^{8,9,21}$. It was shown that there was a higher mortality in trauma patients, who underwent surgery, admitted at night, and on weekends. After multivariate logistic regression analysis, age, red risk rating and night admission were identified as independent predictors of mortality, which was not observed for admissions over the weekend. Thus, age is an intrinsic factor to the patient, and the severity is an intrinsic factor to the mechanism of injury $11,22,23$. On the other hand, night admission is presented, therefore, as an intrinsic factor of systemic error $^{22-24}$.

Reason et al. ${ }^{23}$ proposed a model that defines the error, or an unfavorable outcome in the case of medicine, as something systematic and to avoid them, there are numerous defense barriers. These barriers act as a Swiss cheese slices, each of which has intrinsic flaws, but an error to be realized must be a confluence of failures in all the barriers. The "Swiss Cheese Model" 23,24, brings a different analysis of the error, that instead of being seen as a consequence of a personal failure, is understood as a consequence of several factors that increase the chance of an error occurs. In this study, the various adverse conditions during the night shift already mentioned would be represented as new "holes" in the supervision and safety barrier, contributing to the higher incidence of adverse outcomes ${ }^{24}$.

The fact that the causal error condition arise from potentially identifiable factors, and not appended the human factor, allows a better interpretation and a search for a permanent solution to the problem at hand. Because correct logistical failures is more viable than changing human behavior, this interpretation becomes of great value to the improvement of results.

Great centers of reference, with long-term established services have not identified differences in mortality in the "off-hours" period ${ }^{4,9,10}$. This fact points to the idea that the various adverse conditions (holes in the barriers) can and should be neutralized through critical analysis of the context of each service and higher organizational level. These studies suggest that the relationship between level of organization and higher mortality in the periods "off hours" should be recognized and used as an important indicator to improve care processes as well as the reformulation of these processes over the years ${ }^{3,4}$.
Although well known for aviation and other business sectors, the Swiss cheese model is misunderstood and poorly put into practice in health care $^{24}$. It is important to understand that the period "off hours" has its organizational peculiarities and should be managed in order to solve these peculiarities, not similar to daytime shift so there is the improvement of services.

Some limitations were found in this study. As this is a cohort study with retrospective collection, it cannot excluded the possibility of other confounding factors were not analyzed.it should be remembered that the assessment of this association involves several potentially confounding factors, such as the definition of daytime and nighttime periods or middle weekend, the population studied, the health service organization studied, as well as numerous other possible variables such as the severity of the trauma. During the study period, they had not been deployed indexes related to trauma (RTS, ISS, TRISS), by using the Manchester Protocol ${ }^{11}$, which was already in use at the hospital. The study limitations are being corrected for improvement of trauma care service as well as the analysis of future studies through a specific procedure for taking care of polytrauma patients. Finally, data were collected in a short period, in a single center and the absence of a calculation to determine the sample size, which may limit its external validity.

The body of evidence suggests that these occurrences are part of a systemic error of the model at the time of the study. The analysis and interpretation of error for a systematic approach enables the effective resolution of the problem through measures to identify the peculiarities of night shift.

In conclusion, trauma patients, who underwent surgery, admitted to the night shift at a major hospital in emergency Salvador, Bahia, had higher in-hospital mortality, regardless of its severity and risk classification. The variables red risk classification, admission to the night shift and age were identified as independent predictors of mortality.

\section{Acknowledgements}

The authors thank Dr. Lycia Cavalcanti and Dr. Jorge Motta who made possible the development of this research project at the Hospital do Subúrbio, in Salvador BA, through a constant management in order to provide a decent service to patients of the unified health system of Brazil (Sistema Único de Saúde - SUS). 


\section{R E S U M O}

Objetivo: verificar o impacto do turno de admissão de pacientes vítimas de trauma, submetidos ao tratamento cirúrgico, na mortalidade hospitalar. Métodos: estudo de coorte observacional retrospectivo no período de novembro de 2011 a março de 2012, com dados coletados através de prontuário eletrônico. Foram analisadas estatisticamente as variáveis de interesse: idade, sexo, cidade de origem, estado civil, classificação de risco à admissão (baseado no Protocolo de Manchester), grau de contaminação, horário/turno de admissão, dia de admissão e desfecho hospitalar. Resultados: Quinhentos e sessenta e três pacientes traumatizados foram submetidos ao tratamento cirúrgico no período estudado, com média de idade de 35,5 anos ( $\pm 20,7)$, sendo $75 \%$ do sexo masculino, 49,9\% admitidos no turno noturno e $36,4 \%$ aos finais de semana. Os pacientes admitidos à noite e aos finais de semana apresentaram maior mortalidade, $6,9 \%$ vs. $2,2 \%, p=0,014$, e 5,4\% vs. 3,9\%, $p=0,014$, respectivamente. À análise multivariada, os fatores preditores independentes de mortalidade foram a admissão noturna $(O R$ 3,15), a classificação de risco vermelho (OR 4,87), e a idade $(O R$ 1,17). Conclusão: a admissão no turno noturno e no final de semana foi associada com pacientes de maior gravidade e apresentaram maior taxa de mortalidade. A admissão no turno noturno foi fator independente de mortalidade em pacientes traumatizados cirúrgicos, juntamente com a classificação de risco vermelho e a idade.

\section{Descritores: Trauma. Mortalidade. Admissão do Paciente. Fatores de Tempo. Emergências.}

\section{REFERENCES}

1. Di Bartolomeo S. The "off-hour" effect in trauma care: a possible quality indicator with appealing characteristics. Scan J Trauma Resusc Emerg Med. 2011;19:33.

2. O'Dwyer GO, Oliveira SP, Seta MH. Avaliação dos serviços hospitalares de emergência do programa QualisUS. Ciênc saúde coletiva. 2009;14(5):1881-90

3. Ono $Y$, Ishida $T$, Iwasaki $Y$, Kawakami $Y$, Inokuchi R, Tase $C$, et al The off-hour effect on trauma patients requiring subspecialty intervention at a community hospital in Japan: a retrospective cohort study. Scan J Trauma Resusc Emerg Med. 2015;23:20.

4. Albuquerque GO, Szuster E, Corrêa LCT, Goulart E, Souza AC, Sobrinho ALOA, et al. Análise dos resultados do atendimento ao paciente com infarto agudo do miocárdio com supradesnivelamento do segmento ST nos períodos diurno e noturno. Rev Bras Cardiol Invasiva. 2009;17(1):52-7

5. Jneid $\mathrm{H}$, Fonarow GC, Cannon CP, Palacios IF, Kilic T, Moukarbel $\mathrm{GV}$, et al. Impact of time of presentation on the care and outcomes of acute myocardial infarction. Circulation. 2008;117(19):2502-9.

6. Magid DJ, Wang Y, Herrin J, McNamara RL, Bradley EH, Curtis JP, et al. Relationship between time of day, day of week, timeliness of reperfusion, and in-hospital mortality for patients with acute ST-segment elevation myocardial infarction. JAMA. 2005;294(7):803-12

7. Degenhardt N. Increased mortality among the critically ill patients admitted on weekends: a global trend. Dynamics. 2011;22(3):148.

8. Takada JY, Roza LC, Ramos RB, Avakian SD, Ramires JAF, Mansur AP. Hora da admissão na unidade de emergência e mortalidade hospitalar na síndrome coronária aguda. Arq Bras Cardiol. 2012:98(2):104-10.

9. Casella G, Ottani F, Ortolani P, Guastaroba P, Santarelli A, Balducelli $M$, et al. Off-hour primary percutaneous coronary angioplasty does not affect outcome of patients with ST-Segment elevation acute myocardial infarction treated within a regional network for reperfusion: The REAL (Registro Regionale Angioplastiche dell'Emilia-Romagna) registry. JACC Cardiovasc Interv. 2011;4(3):270-8

10. Siudak Z, Rakowski T, Dziewierz A, Skowronek J, Rutka J, Bagieñski $M$, et al. Primary percutaneous coronary intervention during on" vs off"hours in patients with ST"elevation myocardial infarction. Results from EUROTRANSFER Registry. Kardiol Pol. 2011;69(10):1017-22

11. Souza CC, Toledo AD, Tadeu LFR, Chianca TCM. Risk classification in an emergency room: agreement level between a Brazilian institutional and the Manchester Protocol. Rev Latino-Am Enfermagem. 2011;19(1):26-33.
12. Mangram AJ, Horan TC, Pearson ML, Silver LC, Jarvis WR. Guideline for Prevention of Surgical Site Infection, 1999. Centers for Disease Control and Prevention (CDC) Hospital Infection Control Practices Advisory Committee. Am J Infect Control. 1999;27(2):97-132.

13. Organização Mundial da Saúde. CID-10 Classificação Estatística Internacional de Doenças e Problemas Relacionados à Saúde. 10ª rev. São Paulo: Universidade de São Paulo; 1997.

14. Kuijsten HA, Brinkman S, Meynaar IA, Spronk PE, van der Spoel J, Bosman RJ, et al. Hospital mortality is associated with ICU admission time. Intensive Care Med. 2010;36(10):1765-71.

15. Laupland KB, Misset B, Souweine B, Tabah A, Azoulay E, GoldgranToledano $D$, et al. Mortality associated with timing of admission to and discharge from ICU: a retrospective cohort study. BMC Health Serv Res. 2011;11:321

16. Ryan JW, Peterson ED, Chen AY, Roe MT, Ohman EM, Cannon $C P$, et al. Optimal timing of intervention in non-ST-segment elevation acute coronary syndromes: insights from the CRUSADE (Can Rapid risk stratification of Unstable angina patients Suppress ADverse outcomes with Early implementation of the ACC/AHA guidelines) Registry. Circulation. 2005;112(20):3049-57.

17. Al-Lawati JA, Al-Zakwani I, Sulaiman K, Al-Habib K, Al Suwaidi J, Panduranga $P$, et al. Weekend versus weekday, morning versus evening admission in relationship to mortality in acute coronary syndrome patients in 6 middle eastern countries: results from gulf race 2 registry. Open Cardiovasc Med J. 2012;6:106-12.

18. Mohammed MA, Sidhu KS, Rudge G, Stevens AJ. Weekend admission to hospital has a higher risk of death in the elective setting than in the emergency setting: a retrospective database study of national health service hospitals in England. BMC Health Serv Res. 2012;12:87.

19. Mitra B, Cameron PA, Fitzgerald MC, Bernard S, Moloney J, Varma $D$, et al. "After-hours" staffing of trauma centres and outcomes among patients presenting with acute traumatic coagulopathy. Med J Aust. 2014:210(10):588-91.

20. Laupland KB, Ball CG, Kirkpatrick AW. Hospital mortality among major trauma victims admitted on weekends and evenings: a cohort study. J Trauma Manag Outcomes. 2009;3:8.

21. Egol KA, Tolisano AM, Spratt KF, Koval KJ. Mortality rates following trauma: The difference is night and day. J Emerg Trauma Shock. 2011;4(2):178-83.

22. Pinto Junior D, Salgado PO, Chianca TCM. Predictive validity of the Manchester Triage System: evaluation of outcomes of patients admitted to an emergency department. Rev Latino-Am Enfermagem. 2012;20(6):1041-7.

23. Reason JT, Carthey J, de Leval MR. Diagnosing "vulnerable system syndrome": an essential prerequisite to effective risk management. Qual Health Care. 2001;10 Suppl 2:ii21-5. 
24. Perneger TV. The Swiss cheese model of safety incidents: are there holes in the metaphor? BMC Health Serv Res. 2005;5:71.

Received on 05/01/2015

Accepted for publication 15/03/2015

Conflict of interest: none.

Source of funding: none.
Address for correspondence:

André Gusmão Cunha

E-mail: dr.andregusmao13@gmail.com 